\title{
Erliquiose nos animais e no homem
}

\author{
Animal and human Ehrlichiosis
}

\author{
Ana Silvia Dagnone1; Hélio Silva Autran de Morais²; Odilon Vidotto³ *
}

\begin{abstract}
Resumo: A erliquiose é uma doença causada por bactérias gram negativas estritamente intracelulares, pertencentes a Ordem Rickettsiales, Família Anaplasmataceae, Gêneros Ehrlichia e Anaplasma. As diferentes erlíquias podem parasitar leucócitos, eritrócitos e plaquetas levando a alterações em vários órgãos. Os sinais clínicos variam com a severidade da infecção, a resposta imunológica do hospedeiro, os órgãos atingidos, a espécie de erlíquia envolvida e a presenca de co-infecção com outras erlíquias ou outros microrganismos transmitidos pelo mesmo vetor. A incidência de erliquiose vem aumentando nos últimos anos tanto nos animais como no homem. O diagnóstico etiológico é importante para o monitoramento epidemiológico, porém a maioria dos testes usados rotineiramente apresenta limitações. A recente introdução de técnicas diagnósticas que empregam biologia molecular permitem caracterizar quais espécies de erlíquia estão infectando o paciente.
\end{abstract}

Palavras-chave: Erliquiose, Erhlichia sp., animais, homem, diagnóstico.

Abstract: Ehrlichiosis is a disease caused by gram negative obligate intracellular bacterial organisms belonging to the Rickettsiales Order, Anaplasmataceae Family, Genus Ehrlichia and Anaplasma. These organisms may parasite leukocytes, erythrocytes or platelets, leading to abnormalities in many organs. Clinical signs are variable depending on the severity of the infection, host immune response, affected organs, the specific Ehrlichia species involved, and the presence of coinfection with other Ehrlichiae or tickborne disease. The incidence of ehrlichiosis has increased over the last years in both animals and men. The etiological diagnosis is important for adequate epidemiological monitoring. Most tests currently being used have limitations. The recent use of molecular biology diagnostic techniques allow the characterization of the specie or species that are infecting a given patient.

Key words: Ehrlichiosis, Erhlichia sp., animals, man, diagnosis.

\section{Introdução}

A erliquiose é uma doença causada por bactérias estritamente intracelulares, gram-negativas, pertencentes a Ordem Rickettsiales, Família Anaplasmataceae e gêneros Ehrlichia e Anaplasma (DUMLER et al., 1995, 2001). As espécies destes gêneros causam várias doenças em animais e seres humanos (RIKIHISA et al., 1991), tendo sido reconhecidas inicialmente em 1910, quando Theiler descreveu o Anaplasma marginale, agente etiológico da anaplasmose em bovinos.

Em 1925, Cowdry descreveu o agente Cowdria ruminantum. Posteriormente, em 1935 foi descrita a Rickettsia canis em cães na Algéria, espécie reclassificada em 1945 como Ehrlichia canis (DONATIEN; LESTOQUARD, 1935), sendo estabelecido o Gênero Ehrlichia em 1945 em homenagem ao microbiologista alemão Paul Ehrlich. Em 1940, foi descrita a Ehrlichia phagocytophila. Outras espécies de erliquias foram descritas posteriormente.

As descobertas da erliquiose granulocítica humana, da Ehrlichia sennetsu ("febre sennetsu") e o isolamento da Ehrlichia chaffeensis em seres humanos, mostraram que a erliquose não é apenas um problema médico veterinário (McDADE, 1989; ANDERSON et al., 1991; RIKIHISA,
1991; ANDERSON et al., 1993; BAKKEN et al., 1994; CHEN et al., 1994; FISHBEIN et al., 1994). Recentemente foi descoberto que o agente causador da erliquiose granulocítica humana (EGH) também pode infectar naturalmente várias espécies animais. Da mesma forma, a erliquiose monocítica canina pode ser patogênica para seres humanos. Os organismos causadores de erliquiose humana são virtualmente indistingüíveis das espécies que acometem os animais (WILLIAMS, 1999).

Com base na análise da seqüência do gene $16 \mathrm{~S}$ rRNA, um conjunto geneticamente relacionado de bactérias gram-negativas intracelulares obrigatórias é classificado como erlíquias entre as Protobactérias do subgrupo $\alpha$. As erlíquias são geneticamente diferentes das demais riquétsias (ANDERSON et al., 1991; CHEN et al., 1994). Atualmente três genogrupos distintos do gênero Ehrlichia são identificados com base nas similaridades do gene 16S rRNA (ANDERSON et al., 1991; BORJERSSON, 2000; DUMLER et al., 1995). Estes grupos podem ser designados por protótipos das espécies precedentes historicamente e são apresentados na Tabela 1. A Reação em Cadeia pela Polimerase (PCR) seguida de seqüenciamentos genéticos de espécies encontradas em várias regiões do mundo, permitiu novos agrupamentos e classificações taxonômicas das

\footnotetext{
1 Aluna do Mestrado em Sanidade Animal da Universidade Estadual de Londrina (UEL)

2 Professor Adjunto do Departamento de Clínica Veterinária da UEL

${ }^{3}$ Professor Titular do Departamento de Medicina Veterinária Preventiva, CCA, UEL, Caixa Postal 6001, e-mail: <vidotto@uel.br>

Autor para correspondência.
} 
erlíquias. Recentemente foram propostas alterações de gêneros entre algumas espécies de Ehrlichia, Anaplasma, Neorickettsia e Cowdria (DUMLER et al., 2001). Estas alterações são apresentadas na Tabela 2.

Tabela 1 - Classificação do gênero Ehrlichia através de genogrupos.

Tabela 2 - Espécies de Ehrlichia de acordo com a classificação antiga (coluna à esquerda) e a atual (coluna à direita).

\section{Erliquiose nos Animais \\ 2. 1 Erliquiose monocítica canina}

$O$ agente erliquial mais comum encontrado na erliquiose monocítica canina (EMC) é a E. canis (DONATIEN; LESTOQUARD, 1935), que tem como principal vetor o carrapato marrom do cão Riphicephalus sanguineus (LATREILLE, 1806), embora o Dermacentor variabilis também possa experimentalmente transmitir a E. canis (WANER; HARRUS, 2000). Existem três cepas da $E$. canis: Florida, Oklahoma e Israel (KEYSARY et al., 1996).

A E. canis recebeu atenção especial de 1968 a 1970, quando um grande surto levou a morte quase 300 cães militares do exército dos Estados Unidos no Vietnã (HUXSOLL et al., 1969; HUXSOLL et al., 1970; WALKER et al., 1970; HARRUS et al., 1997a). Em 1987 foi identificado um organismo erliquial, denominado $E$. chaffeensis, como causador da erliquiose monocítica humana. Através do seqüenciamento do gene $16 \mathrm{~S}$ rRNA, verificou-se homologia de $98,2 \%$ entre a $E$. canis e a E. chaffeensis (ANDERSON et al., 1991). A E. chaffeensis pode também naturalmente infectar o cão (MURPHY et al., 1998).

Como o $R$. sanguineus também é transmissor de outros hemoparasitas, é relativamente comum encontrar infecções mistas, com a Babesia canis, Bartonella vinsonii subs. Berkhoffi, e Hepatozoon canis. Infecção por duas ou mais espécies diferentes de erlíquias já foi identificada em cão (KORDICK et al., 1999; MEINKOTH et al., 2001). Não há como diferenciar clinicamente as infecções simples das mistas por E. canis e B. canis em cães (EWING et al., 1965).

Nos carrapatos a E. canis tem transmissão transestadial, mas não transovariana (GROVES et al., 1975; SMITH et al., 1976). As larvas e ninfas se infectam quando se alimentam em um cão com a fase aguda da doença, através da ingestão de leucócitos infectados (SMITH et al., 1976; LEWIS et al., 1977). No carrapato, as erlíquiais se disseminam por hemócitos do intestino para a glândula salivar. Durante a alimentação, os carrapatos inoculam a secreção salivar contaminada com erlíquias no interior do sítio de alimentação no hospedeiro (SMITH et al., 1976). Todos os três estágios podem transmitir a doença (larva, ninfa e adulto). Os carrapatos sobrevivem como adultos sem se alimentar de 155 a 568 dias, e podem transmitir a infecção por até 155 dias após se tornarem infectados (LEWIS et al., 1977).

Os hospedeiros vertebrados mais comuns são os da família Canidae (cães, coiotes, raposa e chacal). Cães em áreas endêmicas e aqueles que são transportados para estas regiões são susceptíveis à doença. $A$ distribuição da EMC está relacionada com a distribuição do carrapato vetor, ocorrendo na Ásia, África, Europae América (KEEF etal., 1982; BREITSCHWERDT, 1995). No Brasil, a presença de E. canis foi descrita no Rio de Janeiro (CARRILO et al., 1976), em São Paulo (HAGIWARA, 1979), no Mato Grosso do Sul (SILVEIRA et al., 1984), no Paraná (YAMAMURA; VIDOTTO, 1982) e no Rio Grande do Sul (SEIBERT et al., 1997).

O período de incubação da EMC é de 8 a 20 dias (HARRUS, 1999). A doença pode apresentar três fases: aguda, subclínica e crônica. A fase aguda dura de duas a quatro semanas (GREENE; HARVEY, 1984). Nela o microrganismo entra nas células mononucleares, se replica por fissão binária, antes de se disseminar para outros órgãos do hospedeiro. Nesta fase, os sinais clínicos são inespecíficos incluindo febre, secreção ocular e nasal, anorexia, depressão, perda de peso, linfadenopatia, vasculite, sinais neurológicos, musculares, oculares e de poliartrite (BELLAH et al., 1986). Os achados laboratoriais mais comuns são trombocitopenia e leucopenia. A trombocitopenia na fase aguda pode ocorrer por aumento no consumo de plaquetas pelo endotélio vascular inflamado, aumento no seqüestro esplênico e destruição imunomediada ou por diminuição da vida média das plaquetas. Ocorre também alteração na função das plaquetas, com muitos animais apresentando sangramento superficial, mesmo com o número de plaquetas e perfil de coagula-ção normais (HARRUS, 1999). Após a fase aguda o animal pode se curar, ou entrar na fase subclínica, onde os sinais clínicos desaparecem, mas a riquétsia se mantém no organismo. Esta fase pode persistir por anos (NYINDO et al., 1980; CODNER, 1986; BARTSCH, 1996; WANER et al., 1997). Cães imunocompetentes eliminarão o parasita (HIBBLER et al., 1986), enquanto que os cães com resposta imunológica insuficiente entrarão na fase crônica da doença. Em cães infectados experimentalmente, o 
achado laboratorial mais freqüente na infecção erliquial sublínica foi a trombocitopenia, associada com altos títulos de anticorpos contra E. canis (WANER et al., 1997). A fase crônica desenvolve-se em alguns animais após a fase subclínica e pode variar de leve a severa. Na severa, ocorre comprometimento da medula óssea com pancitopenia (WALKER et al., 1970). Óbito por hemorragias secundárias à trombocitopenia, trombocitopatias (HARRUS, 1999) ou infecções secundárias (HUXSOLL et al., 1970) pode ocorrer nesta fase. Cães da raça Pastor Alemão parecem desenvolver a doença de forma mais severa do que outras raças (HIBBLER et al., 1986). Hipergamaglobulinemia persistente pode ocorrer em todas as fases da doença (WOODY; HOSKINS, 1991; BREITSCHWERDT, 1995; HARRUS et al., 1996).

Ao contrário das demais riquétsias, as erlíquias se replicam dentro de fagossomos da célula hospedeira (McDADE, 1989; VANDERBILT MEDICAL CENTER, 1998). O ciclo de desenvolvimento da $E$. canis em monócitos caninos tem três estágios (NYINDO et al., 1971): 1) Os corpos elementares entram nos monócitos por fagocitose. A fusão fagolisossomal não ocorre em células infectadas, permitindo aos corpos elementares crescerem e se dividirem dentro dos limites do fagossomo. A multiplicação ocorre por fissão binária. 2) Três a cinco dias pós infecção um pequeno número de corpos elementares em agrupamentos de 1 a $2 \mu$ m de diâmetro, denominados corpúsculos iniciais são observados como inclusões pleomórficas. 3) Nos sete a 12 dias subseqüentes, ocorrem crescimento adicional e multiplicações. Os corpúsculos iniciais desenvolvem-se para inclusões maduras, que na microscopia óptica têm aspecto de "amora", as chamadas mórulas (Figura 1), que tipificam o gênero. Os monócitos infectados, geralmente apresentam mórulas e cada mórula contém vários corpos elementares. As mórulas liberam corpos elementares quando as células infectadas se rompem ou então são liberadas por exocitose e o ciclo infeccioso é repetido.

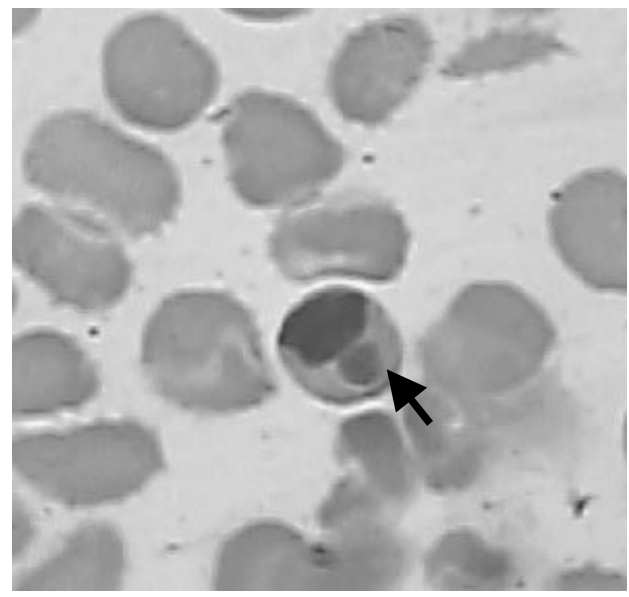

Figura 1 - Fotomicrografia de esfregaço de papa de leucócitos de um cão com erliquiose aguda, mostrando célula mononuclear (monócito) contendo uma mórula no seu interior (seta). Microscopia Óptica, aumento original X 1000, Corante Wright.

Mecanismos imunológicos possivelmente estão envolvidos na patogenia da erliquiose, demosntrados por linfadenopatia, esplenomegalia, hiperplasia linforreticular em áreas corticais de linfonodos, acúmulo periportal de células mononucleares, infiltração mononuclear em interstício renal e glomerulonefrite. Alterações imunológicas podem ser evidenciadas em infecção experi-mental com E. canis em cães (CASTRO, 1997). Há intensa infiltração de plasmócitos em órgãos parenquimatosos, e os animais apresentam teste de Coombs e de autoaglutinação positivos (HARRUS, 1999). Ocorrem também infiltrado perivascular nos pulmões, rins, baço, meninges e olhos. O baço participa no seqüestro e na destruição de leucócitos e de plaquetas (HARRUS, 1999).

\subsection{Erliquiose granulocítica canina}

O principal agente erliquial que infecta os granulócitos de cães (neutrófilos e eosinófilos) é a E. ewingii, tendo como possíveis vetores o carrapato Amblyomma americanum e o Otobius megnini. Ela causa doença moderada a grave, com claudicação, trombocitopenia e edema articular (STOCKHAM et al., 1990). Além da E. ewingii, a E. equi (Anaplasma phagocytophilum) também causa erliquiose granulocítica canina (EGC). A E. equi (LEWIS et al., 1975; MADIGAN, 1993) tem como hospedeiros naturais além do cão, o homem, eqüínos e lhamas e experimentais, os muares, ovinos, caprinos, gatos e primatas não humanos. O vetor conhecido é o carrapato Ixodes ricinus. No cão pode também ser transmitida pelo $R$. sanguineus (HIBLER et al.,1986), causando doença clínica moderada com trombocitopenia. A E. ewingii através da análise da seqüência do gene 16S rRNA, apresenta grande semelhança genética com o agente da erliquiose granulocítica humana (EGH) (Anaplasma phagocytophilum) (CHEN et al., 1994; CHAE et al., 2000), e com a E. phagocytophila (Anaplasma phagocytophilum) (ANDERSON et al., 1991), porém a semelhança é maior com a E. chaffeensis (DUMLER et al., 1995). O agente da erliquiose granulocítica humana (EGH), tem como hospedeiros naturais os cães, seres humanos, equinos e ratos do pé branco e experimentais ratos e cervos. O principal vetor conhecido é o Ixode scapularis. A E. phagocytophila (agente da "febre da picada do carrapato"), tem como hospedeiros naturais os cães, ovinos, caprinos, bovinos, bisões, cervos, Ihamas e humanos e experimentais cobaias e ratos. Apresenta semelhança genética com o agente da EGH (DUMLER et al., 1995). Seus vetores conhecidos são o I. ricinus (CINCO et al., 1997), I. scapularis e I. pacificus (BARLOUGH et al., 1997). Causa doença leve a moderada em cães. Tais semelhanças genéticas estão reformulando as classificações e possivelmente tais espécies granulocíticas serão incluídas com uma única espécie (DUMLER et al., 2001).

\subsection{Erliquiose Trombocítica Canina}

O agente etiológico da erliquiose trombocítica canina (ETC) é a Ehrlichia platys (Anaplasma platys) (HARVEY, 1978; FRENCH et al., 1983), que infecta as plaquetas do cão, podendo eventualmente infectar também os 
leucócitos. É visualizada como inclusões basofílicas no interior de plaquetas em esfregaços corados com corante de Giemsa. O vetor conhecido é o $R$. sanguineus. A ETC é uma doença que pode variar de leve a severa no cão (HARVEY et al., 1998). É caracterizada por trombocitopenia cíclica com parasi-temia inicial onde um grande número de plaquetas são parasitadas. Alguns dias após a infecção há uma diminuição brusca no número de plaquetas e as erlíquias desaparecem da circulação. A contagem plaquetária retorna a valores próximos aos de referência em aproximadamente quatro dias. A parasitemia e trombocitopenia subseqüentes tendem a ocorrer periodi-camente em intervalos de uma a duas semanas. Por este motivo, a doença também é conhecida como trombocitopenia cíclica canina. Com a diminuição do número de plaquetas infectadas a trombocitopenia pode continuar severa ou diminuir de intensidade. Os sinais clínicos começam após um período de incubação de oito a 15 dias, com alguns sinais digestivos, anorexia e distúrbios hemostáticos (BEUAFILS, 1999). O diagnós-tico é feito utilizando-se os mesmos métodos utilizados para $E$. canis, sendo a reação em cadeia pela polime-rase (PCR) o método mais confiável, porque a sorologia apresenta reações cruzadas (CHANG et al., 1996).

\subsection{Erliquiose felina}

As espécies de erlíquias que naturalmente infectam felinos ainda não foram caracterizadas, entretanto, recentemente material genômico de E. canis proveniente de gatos naturalmente infectados foi amplificado,clonado e sequenciado (BREITSCHWERDT, et al., 2001). Corpúsculos de inclusão e mórulas já foram encontrados em células sangüíneas mononucleares e polimorfonucleares periféricas de gatos (BOULOY et al., 1994). Gatos podem ser infectados experimentalmente com E. equi (LEWIS et al., 1975) e E. risticii (DAWSON et al., 1996). Anticorpos contra E. canis e E. risticii ocorrem em gatos de alguns estados norte americanos (LAPPIN et al., 1998). Os vetores da erliquiose felina não são conhecidos. A patogenia possivelmente é semelhante à da $E$. canis.

A sintomatologia na maioria dos casos é inespecífica e pode ter sido causada por outra doença concomintante (letargia, febre, anorexia, perda de peso, esplenomegalia, linfadenomegalia, mucosas pálidas). Infecções concomitantes com Mycoplasma haemofelis (Haemobartonella felis) (BEAUFILS, 1999), Vírus da Leucemia Felina e Vírus da Imunodeficiência Felina, e ocorrência simultânea de linfossarcoma são comuns. O diagnóstico e terapia são semelhantes aos utilizados para a erliquiose canina (LAPPIN et al., 1998). Como ainda não estão definidas as vias de transmissão da infecção natural, a exposição a artrópodes e ingestão de roedores devem ser evitadas.

\subsection{Outras espécies de Ehrlichia encontradas nos animais}

Outras espécies de erlíquias podem infectar células mononucleares: E. chaffeensis (erliquiose monocítica humana), tendo como vetores conhecidos o Amblyomma americanume Dermacentor variabilis. Tem como hospedeiros naturais conhecidos o cão, seres humanos e cervos, enquanto que experimentalmente podem ser infectados os cães, cervos da cauda branca e ratos de pés brancos. A infecção no cão pode ser subclínica ou leve (KORDICK et al., 1999). A E. chaffeensis também foi encontrada em coiotes através da PCR, portanto estes animais podem ser reservatórios potenciais para esta erlíquia (KOCAN et al., 2000). A E. risticii (Neorickettsia risticii) (erliquiose monocítica eqüína) (HOLLAND et al., 1985; KNOWLES et al., 1983), tem como vetor suspeito possível o trematódeo Nanophytes salmincola que infecta lesmas operculadas do gênero Juga (BARLOUGH et al., 1998). Infecta principalmente monócitos, causando infecção leve em cães (trombocitopenia, poliartropatias, anemia, letargia e vômitos). Em eqüínos, a E. risticii causa uma doença clínica severa conhecida como a Febre do Rio Potomac (KNOWLES et al., 1983), que pode apresentar como sinais clínicos: pirexia, anorexia, enterite, diarréia aquosa, cólica e laminite. A E. equi (LEWIS et al., 1975), já citada anteriormente como agente infeccioso natural de cães também infecta células polimorfonucleares de eqüínos, com vetor $I$. ricinus. Os sinais clínicos mais comuns nos eqüínos são febre, anorexia, hemorragias petequiais e edema de membros (MADIGAN et al., 1993). Em bovinos, a Ehrlichia bovis (Anaplasma bovis) pode ser transmitida pelo carrapato Hyalomma sp, e infecta células mononucleares. Causa a doença conhecida como "Nopi" ou "Nofel" com sinais clínicos que incluem febre, anorexia, incoordenação e linfadenomegalia. Ocorre na África, India e Srilanka (MATHEW; EWING, 2001). No Brasil há descrição de ocorrência principal-mente no Estado do Rio de Janeiro (MASSARD et al., 1982).

\section{Ehrlichia spp em seres humanos}

A infecção em seres humanos por um microrganismo muito semelhante à $E$. canis foi descrita pela primeira vez em 1987 (MAEDA et al., 1987; FISHBEIN et al. 1987), com um paciente apresentando febre, milagia, fraqueza e confusão mental. A erliquiose humana é uma causa comum de hospitalização por doença febril de causa desconhecida na Geórgia (EUA), sendo mais comum nesta região que a febre maculosa (FISHBEIN et al., 1989).

Crianças com quadros clínicos diversos com sorologias positivas para $E$. canis foram descritos (DORAN et al.; 1989; GOLDEN, et al., 1989). Altas taxas de soropositividade para E. canis em seres humanos com sintomas clínicos diversos ocorrem em algumas regiões dos Estados Unidos (ENG et al., 1990), tendo ocorrido um surto de erliquiose humana em soldados do exército americano em uma área onde a doença de Lyme era endêmica (PETERSEN et al., 1989). A erliquiose granulocítica humana pode apresentar-se com manifestações de pancardite, podendo causar a morte (JAHANGIR et al., 1998). Quadros clínicos bastante diversos podem ocorrer em seres humanos infectados com E. chaffeensis (SEXTON et al., 1998; PATEL et al., 1999; WEAVER et al., 1999). 
Na década de 90 foram observados os primeiros casos de EMC (MORAIS et al., 1991) e granulocítica (PETROVEC et al., 1997) em genes humanos na Europa. O diagnóstico da EGH foi estabelecido através da soroconversão de $E$. equi e agente da EGH e também através da PCR. O caso descrito foi moderado e resolveu expontaneamente. Em 1996 foi descrito o primeiro caso de erliquiose humana na Venezuela (ALVARADO et al.).

\section{Diagnóstico}

A erliquiose é uma "zoonose emergente" (BORJERSSON, 2000), cujo reconhecimento precoce é importante. As técnicas de diagnóstico utilizadas são as mesmas para todas as espécies conhecidas até 0 momento.

\subsection{Hematologia}

$\mathrm{Na}$ fase aguda pode ocorrer anemia, trombocitopenia, pancitopenia, linfocitose granular e leucopenia leve (HUXSOLL et al.,1970; WOODY; HOSKINS, 1991; KUEHN et al., 1985; BELLAH et al., 1986; CODNER et al., 1986; HARRUS et al., 1996). Na fase crônica é comum haver trombocitopenia (SMITH et al., 1975), leucopenia e anemia mais severas (WOODY; HOSKINS, 1991).

\subsection{Provas bioquímicas}

Podem ser encontradas alterações como hipoalbuminemia,hiperglobulinemia, hipergamaglobulinemia, aumento da alanima amino transferase (ALT) e da fosfatase alcalina (BURGHEN et al., 1971; CODNER et al., 1986; PERILLE et al., 1991; WOODY; HOSKINS, 1991).

\subsection{Detecção de Ehrlichia sp.}

A Ehrlichia pode ser visualizada como corpúsculos de inclusão (Elias, 1991) ou mórulas (Figura 1) (SIMPSON et al., 1972; HILDEBRANDT et al., 1973 ; CARRILO et al., 1978; BURR et al., 1982) em leucócitos e plaquetas em esfregaços sangüíneos feitos de sangue total ou papa de leucócitos (EVERMANN, 1999), líquido cefalorraquidiano, líquido sinovial, aspirados de medula óssea e baço. O teste da hemolinfa pode detectar organismos ricketsiais em carrapatos (BURGDORFER et al., 1970). As mórulas de E. canis são difíceis de serem detectadas, porque a riquétsia está presente em baixas concentrações (TROY et al., 1980; DUPLESSIS et al., 1990), e a proporção de células infectadas pode ser menor do que $1 \%$ (COWELL et al., 1988). Em um estudo realizado em cães com infecção por E. canis na fase aguda da doença, apenas $4 \%$ dos esfregaços tiveram a presença de mórulas (WOODY; HOSKINS, 1991). As formas de $E$. canis demonstradas através da coloração de Giemsa são idênticas as obtidas em imunofluorescência (CARTER et al., 1971).

Cães sadios inoculados experimentalmente com $E$. canis apresentaram sinais clínicos, conversão sorológica e presença de antígenos erliquiais 15 a 20 dias após a inoculação (WANER et al., 1996). Porém o período de permanência deste antígeno no sangue é relativamente curto e variável.

\subsection{Sorologia}

Testes de Imunofluorescência Indireta (IFI) foram desenvolvidos para a detecção de anticorpos séricos (RISTIC et al., 1972). A maior desvantagem da IFI é o grande número de reações inespecíficas originadas por antígenos comuns a outros agentes do mesmo grupo de erlíquias (RIKIHISA et al., 1991; DUMLER et al., 1995; WANER; HARRUS, 2000). Há uma forte reação cruzada entre E. canis e E. sennetsu (RISTIC et al., 1981). Em um estudo realizado com cães militares e civis sadios, a forma predominante da doença foi a subclínica, pois estes animais apresentaram uma alta taxa de anticorpos contra E. canis sem sintomatologia clínica (KEEFE et al., 1982). Em soro de 172 cães com sinais clínicos vagos (pirexia, depressão, anorexia ou apetite seletivo, perda de peso, sangramento, aumento de linfonodos e infestação por carrapatos), a IFI foi positiva em $68,6 \%$ dos animais (TRESAMOL et al., 1998). Os anticorpos de cães infectados com $E$. canis reagem tanto com um antígeno de $E$. canis ( $27 \mathrm{Kda}$ ) como com um de Cowdria ruminatium (25 e 32 Kda) (KELLY et al., 1994). O teste de IFI em soros de 60 cães e 187 cavalos anteriormente testados apenas para Borrelia burgdorferi (Doença de Lyme), detectou $11,7 \%$ dos soros dos cães positivos para $E$. canis (1:40), e dos eqüínos $9,1 \%$ de positivos para E. risticii (MAGNARELLI; ANDERSON, 1993). A detecção de anticorpos para E. canis também pode ser feita através do teste de dot-blot ELISA. Este método não requer equipamento sofisticado, mostrandose tão sensível e específico quanto a IFI, sendo porém realizado de uma maneira mais rápida (CADMAN et al., 1994).

\subsection{Western blotting}

O Western blotting tem sido utilizado no diagnóstico de erlíquias (IQBAL et al., 1994; IQBAL; RIKIHISA, 1994) e na determinação da diversidade antigênica entre cepas de E. canis (HEGARTY et al., 1997). Ele parece ser menos eficaz do que a PCR na detecção precoce do agente. Normalmente o Western blotting é utilizado para confirmar resultados da imunofluorescência. Por causa dos custos adicionais envolvidos, a técnica de PCR, atualmente, parece ser economicamente mais viável (SUKASAWAT et al., 2000).

\subsection{Cultivo}

As erlíquias de uma forma geral são de difícil cultivo (RIKIHISA et al., 1991). Ehlichia canis pode ser cultivada in vitro em linhagem de células monocíticas caninas (NYINDO et al., 1971; HEMELT et al., 1980). Macrófagos de cães obtidos através de lavagens peritoniais sucessivas e monócitos de sangue periférico são igualmente susceptíveis a infecção pela E. canis (STEPHENSON et al., 1977). A E. risticii pode ser cultivada com sucesso 
em histiócitos humanos (RIKIHISA et al., 1984). A E. risticii e a $E$. sennetsu podem ser isoladas in vitro (HOLLAND et al., 1985). O cultivo do agente da EGH foi realizado com sucesso, em células humanas de leucemia promielocítica (HL60) (GOODMAN et al., 1996). Células endoteliais microvasculares humanas de linhagem contínua (CDC/EU.HMEC-1) podem ser usadas como alternativa para o isolamneto de E. chaffeensis, $E$. canis e $R$. rickettsii em substituição às $\mathrm{DH}-82$ normalmente utilizadas (DAWSON et al., 1993).

\subsection{Reação em cadeia pela polimerase (PCR)}

A PCR está facilitando o diagnóstico das doenças erliquiais e tem auxiliado na classificação taxonômica destes e de outros agentes infecciosos. Auxilia na identificação des carrapatos ou outros artrópodes que podem servir de vetores para as doenças erliquiais (PANCHOLI et al., 1995); distingue quais pacientes permanecem com infecção persistente, e quais animais com altos títulos na imunofluorescência, foram tratados com sucesso (BREITSCHWERDT et al., 1998; KORDICK et al., 1999; SUKASAWAT et al., 2000). A PCR também auxilia na detecção de novas cepas ou variantes de espécies (BAKKEN et al., 1994) e permite a detecção precoce de infecção (em alguns casos até quatro dias pós-infecção). Materiais biológicos que podem ser utilizados para a identificação do organismo incluem o sangue total ou frações celulares, tecidos frescos ou parafinados, medula óssea e carrapatos (STEIN et al., 1992).

Como existem reações cruzadas em exames sorológicos dentro do mesmo genogrupo e, potencialmente entre genogrupos, a identificação da espécie pode não ser estabelecida na maioria dos estudos clínicos que utilizem apenas a sorologia (SUKASAWAT et al., 2000). O teste sorológico também não é capaz de distingüir entre infecção aguda e exposição prévia (RIKIHISA et al., 1994 apud SUKASAWAT et al., 2000). A identificação de espécies através da PCR é importante, porque permite determinar a espécie presente, bem como a presença de co-infecção por duas ou mais espécies.

Uma técnica de PCR denominada Repetitive Element Polymerase Chain Reaction (REP-PCR) (fingerprintings), permite a identificação de espécie ou cepavariante de Ehrlichia, através da utilização de vários oligonucleotídeos iniciadores (primers) de segmentos com pouca variabilidade (DAWSON et al., 1997). O REPPCR revela distâncias e padrões específicos para espécies e cepas bacterianas, mas é limitada a elementos repetidos adjacentes dentro das limitações da extensão da polimerase de aproximadamente $5 \mathrm{~Kb}$. Este PCR demonstra seqüências REP presentes em muitas espécies eubacterianas e estas seqüências podem ser utilizadas como pontes eficientes de locais de iniciação na reação em cadeia pela polimerase para identificar diferentes genomas bacterianos (digitais) (VERSALOVIC et al., 1991).

\section{Tratamento}

A localização intracelular de alguns microrganismos é um fator limitante na eficácia da terapia anti-bacteriana dificultando a erradicação destes patógenos de hospedeiros infectados (DRUGS; THERAPY, 1997). Entre as drogas eficazes no tratamento para erliquioses, as tetraciclinas e seus derivados (doxiciclina) estão entre as que têm maiores probabilidades de eliminar o agente (AMYX et al., 1971; BREITSCHWERDT et al., 1995) e são utilizadas na terapia tanto de seres humanos como de animais. O cloranfenicol é menos eficaz que as tetraciclinas. A enrofloxacina não mostrou valor terapêutico no tratamento de infecção experimental por $E$. canis (NEER et al., 1999).

O Dipropionato de Imidocarb é bastante eficaz no tratamento da erliquiose, principalmente em casos de co-infecção de duas ou mais erlíquias em cães ou com infecção concomitante por Babesia spp (HARRUS et al., 1997b; BREITSCHWERDT, 1999). A terapia de suporte pode ser necessária em casos de anemia grave ou de comprometimento de outros órgãos. A resposta linforreticular e hematopoiética de cães com infecção aguda por E. canis tratados com soro anti-linfócitos e ciclofosfamida foi estudada, e observou-se que a imunossupressão não aumenta a mortalidade nem previne ou modifica significativamente as manifestações clínicas da doença (REARDON et al., 1981). As principais drogas que podem ser utilizadas no tratamento da erliquiose canina são mostradas na Tabela 3.

Tabela 3 - Principais drogas utilizadas no tratamento da erliquiose canina.

Mesmo após o tratamento, o título de anticorpos contra E. canis pode permanecer alto por vários meses e até anos. Animais tratados com sucesso podem se re-infectar (WANER; HARRUS, 2000). Em animais que se tornaram soronegativos também pode-se detectar erlíquias através da PCR em aspirado de baço (HARRUS, 1999). A prevenção da erliquiose consiste basicamente no controle de carrapatos (BECHARA et al., 1994), pois até o momento nenhuma vacina eficaz foi desenvolvida (WANER; HARRUS, 2000).

\section{Aspecto Zoonótico}

A erliquiose é sabidamente uma zoonose (McQUISTON et al., 1999). Casos fatais ocorrem em aproximadamente $5 \%$ dos pacientes humanos com erliquiose monocítica ( $E$. chaffeensis) e em $10 \%$ daqueles com a erliquiose granulocítica (DUMLER et al., 1995). Também é importante o reconhecimento de infecções com dife- 
rentes agentes etiológicos simultaneamente porque elas podem ter sinais clínicos diferentes e não responder a terapia da forma esperada (BREITSCHWERDT et al., 1998; MURPHY et al., 1998; KORDICK et al., 1999).

A erliquiose pode ser fatal, principalmente quando não diagnosticada precocemente, retardando o início da terapia adequada. Quase todas as espécies de erlíquias podem acometer o homem e causar alguma sintomatologia. Infecções por múltiplos agentes (de várias espécies e até mesmo de outros gêneros, como por exemplo Babesia canis), também ocorrem e podem levar a uma sintomatologia atípica e de difícil diagnóstico. Ainda não há descrição molecular das principais espécies de erlíquias que acometem os cães e os seres humanos no Brasil. Os poucos dados epidemiológicos disponíveis atualmente descrevem a distribuição de doenças causadas por riquétsias, especialmente nos Estados Unidos e na Europa. Presume-se então, com base nestes dados, que a maioria dos nossos cães seja acometido pela E. canis (EMC). A E. chaffeensis (DAWSON et al., 1996) foi descrita inicialmente em seres humanos, porém esta espécie de Ehrlichia é patogênica para cães (DAWSON et al., 1992). Cães podem ser carreadores deste agente em regiões endêmicas (KORDICK et al., 1999). Além do $R$. sanguineus, poucas espécies de carrapatos parasitam o cão no Brasil. Nas regiões endêmicas para a Febre Maculosa brasileira (Rickettsia rickettsii) o Amblyomma cajennense é a espécie predominante (DE LEMOS et al., 1997).

\section{Referências}

ALVARADO, C.A. et al. Ehrlichiosis humana: reporte del primer caso en Venezuela. Investigacion Clinica, v.37, n.1, p.35-49, 1996.

AMYX, H.L. et al. Therapeutic and Prophylatic Value of Tetracycline in Dogs Infected with the Agent of Tropical Canine Pancytopenia. Journal of American Veterinary Medicine Association, v.159, n.11, p.1428-1432, 1971.

ANDERSON, B.E. et al.. Ehrlichia chaffeensis, a New Species Associated with Human Ehrlichiosis. Journal of Clinical Microbiology, v.29, n.12, p.2838-2842, 1991.

ANDERSON, B.E. et al. Amblyoma americanum: A Potencial Vector Of Human Ehrlichiosis. American Journal of Medical Hygiene, v.49, n.2, p.239-244, 1993.

BAKKEN, J.S. et al. Human Granulocytic Ehrlichiosis in The Upper Midwest United States. A New Species Emerging? Journal of American Medical Association, July 20, v.272, n.3, p.212-218, 1994.

BARLOUGH, J.E. et al. Ehrlichia phagocytophila Genogroup Rickettsiae in Ixodid Ticks from California Collected in 1995 and 1996. Journal of Clinical Microbiology, v.35, n.8, p.2018-2021, 1997.

BARLOUGH, J.E. et al. Detection of Ehrlichia risticii, the agent of Potomac Horse Fever, in fresh water stream snails (Pleuroceridae: Juga spp) from Northern California. Applied and Environmental Microbiology, v. 64, n.8, p.2888-2893, 1998.

BARTSCH, R.C.; GREENE, R.T. Post-Therapy Antibody Titers in Dogs With Ehrlichiosis: Follow-Up Study on 68
Patients Treated Primarily With Tetracicline and/or Doxycline. Journal of Veterinary Internal Medicine, v.10, n.4, p.271-274, 1996.

BEAUFILS, J.P. Ehrlichiosis - Ehrlichia Platys and other Ehrlichia in cats and dogs. Mondialvet 99 [on line]. Disponível em: <http://www.mondialvet99.com/WSAVA/ CONF/MA...S \% 20 PAR \% 20 LES\% 20 TIQUES/ s26h01beaufils.htm capturado em 08/10/2000>. Acesso em: [2000].

BECHARA, G.H. et al. Immunisation of dogs, hamters and guinea pigs against Riphicephalus sanguineus using crude unfed adult tick extracts. Veterinary Parasitology, v.52, p.7990, 1994.

BELLAH, J.R.; SHULL,R.M.; SELCER, E.V.S. Ehrlichia canis-related polyarthritis in a dog. Journal of American Veterinary Medicine Association, v.189, n.08, p.922-923, 1986.

BOJERSSON, D. Ehrlichiosis: new perspectives on pathogenesis and diagnosis. Proceedings $18^{\text {th }}$ ACVIM, Seatle, may, 2000.

BOULOY, R.P. et al. Clinical Ehrlichiosis in a cat. Journal of American Veterinary Medicine Association, v.204, n.9, p. 1475-1478, 1994.

BREITSCHWERDT, E.B. Co-infection with multiple ticktransmitted pathogens. In: James A. Baker Institute (ed), Proceedings for the Canine Infectious Diseases Workshop: From Clinics to Molecular Pathogenesis, 1999. [on line]. Disponível em: <http:// www.ivis.org/proceedings/ Baker_Can_Inf_Dis/Bprd/d09.asp>. Acesso em: [2000]

BREITCHWERDT, E.B. The Rickettioses. In: S.J. Ettinger and E.C. Feldman (Ed), Textbook of Veterinary Internal Medicine. Diseases of the Dog and Cat. W.B. Saunders Company, p.376-383, 1995.

BREITSCHWERDT, E.B. et al. Molecular evidence of Ehrlichia canis infection in cats from North America. Proceedings of the $19^{\text {th }}$ ACVIM, Denver, CO, 2001.

BREITSCHWERDT, E.B.; HEGARTY, B.C.; HANCOCK, S.I. Sequential evaluation of dogs naturally infected with Ehrlichia canis, Ehrlichia chaffeensis, Ehrlichia equi, Ehrlichia ewiingii, or Bartonella vinsonii. Journal of Clinical Microbiology, v.36, n.9, p.2645-2651, 1998.

BURGDORFER, W. Hemolymph Test. A technique for Detection of Rickettsiae in Ticks. The American Journal Tropical Medicine and Hygiene, v.19, n.06, p.1010-1014, 1970.

BURGHEN, G.A. et al. Development of Hypergammaglobulinemia in tropical canine pnacytopenia. Am. J. Vet. Res., v.32, n.5, p.749-756, 1971.

BURR, E.W. Methods for diagnosis of Babesia canis, Ehrlichia canis, and Haemobartonella canis. The Indian Veterinary Journal, v.59, n.12, p.984-987, 1982.

CADMAN, H.F. et al. Comparison of the dot-blot enzyme linked immunoassay with immunofluores-cence for detecting antibodies to Ehrlichia canis. The Veterinary Record, v.135, p.362, October, 1994.

CARRILLO, J.M.; GREEN, R.A. A case report of Canine Ehrlichiosis:Neutrophilic Strain. Journal of American Animal Hospital Association, v.14, p.100-104, 1978.

CARTER, G.B.; SEAMER, J.; SNAPE, T. Diagnosis of tropical canine pancytopenia (Ehrlichia canis infection) by 
immunofluorescence. Research in Veterinary Science, v.12, p.318-322, 1971.

CASTRO, M.B. Avaliação das alterações hematológicas, imunológicas e anatomohistopatológicas na infecção aguda experimental de cães por Ehrlichia canis (Donatien \& Lestoquardt, 1935) MOSHKOVSKY 1945. Dissertação (Mestrado) - Universidade Estadual Paulista - FCAV, Jaboticabal - SP, 1997.

CHAE, J-S. et al. Comparison of the nucleotide sequences of 16S rRna, 444 Ep-ank, and groeESL heat shock operon genes in naturally occuring Ehrlichia equi and human granuloytic ehrlichiosis agent isolates from Northen California. Journal of Clinical Microbiology, v.38, n.04, p.1364-1369, 2000.

CHANG, W.L; PAN, M.J. Specific Amplification of Ehrlichia platys DNA from Blood Specimens by Two-Step PCR. Journal of Clinical Microbiology, v.34, n.12, p.3142-3146, 1996.

CHEN, S.M. et al. Identification of a Granulocytotropic Ehrlichia Species as the Etiologic Agent of Human Disease. Journal of Clinical Microbiology, v.32,n.03, p.589-595, 1994.

CINCO, M. et al. Coexistence of Ehrlichia phagocytophila and Borrelia burgdorferi Sensu Lato in Ixodes ricinus Ticks from Italy as Determined by 16s rRna Gene Sequecing. Journal of Clinical Microbiology, v.35, n.12, p.3365-3366, 1997.

CODNER, E.C.; FARRIS-SMITH, L.L. Characterization of the subclinical phase of ehrlichiosis in dogs. Journal of American Veterinary Medicine Association, v.189, n.01, p.47-50, 1986.

COWELL, R.L. et al. Ehrlichiosis and polyartritis in three dogs. Journal of American Veterinary Medicine Asso-ciation, v.192, n.08, p.1093-1095, 1988.

DAWSON, J.E. et al. Polymerase chain reaction evidence of Ehrlichia chaffeensis, an etiologic agent of human ehrlichiosis, in dogs from southeast Virginia. American Journal of Veterinary Research , v.57, n.08, p.1175-1179, 1996.

DAWSON, J.E. et al. Human endothelial cells as na alternative to DH82 cells for isolation of Ehrlichia chaffeensis, E. canis, and Ricketttsia rickettsii. Pathobiology, v.61, p.293-296, 1993.

DAWSON, J.E.; EWING, S.A. Susceptibility of dogs to infection with Ehrlichia chaffeensis, causative agent of human ehrlichiosis. American Journal of Veterinary Research, v.53,n.08, p.1322-1327, 1992.

DAWSON, J.E. et al. Fingerprinting of Ehrlichia species by repetitive element polymerase chain reaction. The American Journal of Tropical Medicine and Hygiene, v.57, n.01, p.109-114, 1997.

De LEMOS, E.R. et al. Epidemiological aspects of the Brazilian spotted fever: seasonal activity of ticks collected in na endemic area in São Paulo, Brazil. Revista da Sociedade Brasileira de Medicina Tropical , v.30, n.03, p.181-185, 1997.

DONATIEN, A.; LESTOQUARD, F. Existence en Algérie d'une Rickettsia du chien. Bulletin de la Société de Pathologie Exotique et de ses filiales de l'Ouest- Africain et de Madagascar, Siege de la société : Institut Pasteur, Paris, Masson \& Cie., Éditeurs, Libraires de L'Académie de Medicine, 1935, p.418-419.
DORAN, T.I. et al.. Infection with Ehrlichia canis in a child. The Journal of Pediatrics, v.114, n.05, p.809-812, 1989.

DRUGS \& THERAPY PERSPECTIVES (TM). Optimum treatment of intracelular infections is based on clinical data, v.10, n.11, p.8-11, 1997. Adis International Limited. [on line]. Disponível em: <http://pharmacotherapy. medscape.com/ adis/DTP/1997/v.10.n11/dtp1011..03/dtp1011.03.htmL>. Acesso em: 20 out. 2000 .

DUMLER, J.S. et al. Serologic Cross-Reactions among Ehrlichia equi, Ehrlichia phagocytphila, and Human Granulocytic Ehrlichia. Journal of Clinical Microbiology, v.33, n.05, p.1098-1103, 1995.

DUMLER, J.S. et al. Reorganization of genera in the families Rickettsiaceae and Anaplasmataceae in the order Rickettsiales: unification of some species of Ehrlichia with Anaplasma, Cowdria with Ehrlichia and Ehrlichia with Neorickettsia, descriptions of six new species combinations and designation of Ehrlichia equi and "HGE agent' as subjective synonyms of Ehrlichia phagocytophila. Int. J.Syst. Evol. Microbiol., v.51, p. 2145-2165, 2001.

DUPLESSIS, J.L. et al. Conwrrent babesiosis and ehrlichiosis in the dog: blood smear examination supplemented by the indirect fluorescent antibody test, using Cowdria rumminantium as antigens. The Onder Stepoort Journal of Veterinary Research, v.57, n. 3, p.151158, 1990.

ELIAS, E. Diagnosis of ehrlichiosis from the presence of inclusion bodies or morulae of E.canis. Journal of Small Animal Practice, v.33, p.540-543, 1991.

ENG, T.R. et al. Epidemilogic, Clinical, and Laboratory Findings of Human Ehrlichiosis in The United States, 1988. Journal of American Medical Association, v.164, n.17, p.2251-2258, 1990.

EVERMANN, J.F. Diagnostic Strategies for current and emerging canine infectious diseases. Proceedings for the canine infectious diseases workshop: From clinics to molecular pathogenesis. In: James A. Baker Institute (ed), Proceedings for the Canine Infectious Diseases Workshop: From Clinics to Molecular Pathogenesis, 1999. [on line]. Disponível em: <http:// www.ivis.org/proceedings/ Baker_Can_Inf_Dis/Bprd/d06.asp>. Acesso em: 13 out. 2000.

EWING, S.A.; BUCKNER, R.G. Manifestations of Babesiosis, Ehrlichiosis, and combined infections in the dog. American Journal of Veterinary Research, v.26, n.113, p.815-828, 1965.

FISHBEIN, D.B.; DAWSON, J.E.; ROBINSON, L.E. Human Ehrlichiosis in the United States, 1985 to 1990. Annals of Internal Medicine , v.120, n.09, p.736-743, 1994.

FISHBEIN, D.B. et al.Human Ehrlichiosis: Prospective Active Surveillance in Febrile Hospitalized Patients. The Journal of Infecious Diseases, v.160, n.05, p.803-809, 1989.

FISHBEIN, D.B. et al. Unexplained Febrile Illnesses After Exposure to Ticks. Journal of American Medical Association, v.257, n.22, p.3100-3104, 1987.

FRENCH, T.W.; HARVEY, J.W. Serologic Diagnosis of infectious cyclic thrombocytopenia in dogs using an indirect fluorescent antibody test. American Journal of Veterinary Research, v.44, n.12, p.2407-2411, 1983.

GOLDEN, S.E.; SPRINGFIELD, M.O. Aseptic meningitis associated with Ehrlichia canis infection. The Pediatric Infectious Diseases Journal, v.08, n.05, p.335-337, 1989. 
GOODMAN, J.L. et al. Direct cultivation of the causative agent of Human Granulocytic Ehrlichiosis. The New England Journal of Medicine, v.334, n.04, p.209-215, 1996.

GREENE, C.E.; HARVEY, J.W. Canine Ehrlichiosis. In GREENE, C.E. (ed): Clinical Microbiology and Infectious Diseases of the Dog and Cat, Philadelphia, W.B. Saunders, p.545-561, 1984.

GROVES, M.G. et al. Transmission of Ehrlichia canis to Dogs by Thicks (Rhipicephalus sanguineus ). American Journal of Veterinary Research, v.36, n.07, p.937-940, 1975.

HARRUS, S. In: James A. Baker Institute (ed), Proceedings for the Canine Infectious Diseases Workshop: From Clinics to Molecular Pathogenesis, 1999. [on line]. Disponível em: <http:// www.ivis.org/proceedings/Baker_Can_Inf_Dis/ Bprd/d11.asp >.

HARRUS, S. et al Clinical manifestation of infectous canine cyclic thombocytopenia. The Veterinary Record, v.141, p.247-250, September, 1997a.

HARRUS, S.; BARK, H.; WANER, T. Canine monocytic ehrlichiosis: An update. The Compendium on Continuing Education for the Practicing Veterinarian, v.19, n.04, p.431444, 1997b.

HARRUS, S. et al. Serum protein alterations in canine ehrlichiosis. Veterinary Parasitology, v.66, p.241-249, 1996.

HARVEY, J.W. Canine Thrombocytic Ehrlichiosis. In Greene, C.E; Harvey, J.W. (Ed): Infectious Diseases of the Dog and Cat, Philadelphia, W.B.Saunders, p.147-149, 1998.

HARVEY, J.W.; SIMPSON, C.F.; GASKIN, J.M. Cyclic Thrombocytopenia Induced by a Rickettsia-Like Agent in Dogs. The Journal of Infectious Diseases, v.137, n.02, p.182-188, 1978.

HEGARTY, B.C. et al. Immunoblot analysis of the immunoglobulin $\mathrm{G}$ response to Ehrlichia canis in dogs: an international survey. Journal of Veterinary Diagnostic Investigation, v.09. p.32-38, 1997.

HEMELT, I.E. et al. Serial propagation of Ehrlichia canis in primary canine peripheral blood monocyte cultures. Cornell Veterinary, n.70, p.37-42, 1980.

HIBLER, S.C.; HOSKINS, J.D.; GREENE, C.E. Rickettsial Infections in Dogs . Part II. Ehrlichiosis and Infectious Cyclic Thombocytopenia. Compendium on Continuing Education for The Practicing Veteinarian, v.08, n.02, p.106-114, 1986

HILDEBRANDT, P.K. et al. Ultrastructure of Ehrlichia canis. Infection and Immunity, v.07, n.02, p.265-271, 1973.

HOLLAND, C.J. et al. Isolation, Experimental Transmission, and Characterization of Causative Agent of Potomac Horse Fever. Science, v.227, p.522-524, 1985.

HUXSOLL, D.L. et al. Ehrlichia canis- The causative agent of a haemorrhagic disease of dogs. The Veterinary Record, v.85, p.587, 1969.

HUXSOLL, D.L. et al. Tropical Canine Pancytopenia. Journal of American Veterinary Medicine Association, v.157, n.11, p.1627-1632, 1970.

HYGIENIC LABORATORY. The University of lowa. Human ehrlichiosis update. Hotline Aug 95, v.34, n.02, p.3-4, 1995 [on line]. Disponível em: <http://www.uhl.oiowa.edu/ Publications/Hotline/1995All/ehrlichiosis.htmL>. Acesso em: 8 out. 2000.

IQBAL Z.; RIKIHISA, Y. Reisolation of Ehrlichia canis from
Blood and Tissues of Dogs after Doxycycline Treatment. Journal of Clinical Microbiology, v.32, n.07, p.1644-1649, 1994.

IQBAL, Z.; CHAICHANASIRIWIHAYA, W.; RIKIHISA, Y. Comparison of PCR with Other Tests for Early Diagnosis of Canine Ehrlichiosis. Journal of Clinical Microbiology, v.32, n.07, p.1658-1662, 1994.

JAHANGIR, A. et al. Fatal pancarditis associated with human granulocytic ehrlichiosis in a 44-year-old man. Clinical Infectious Diseases, v.27, n.06, p.1424-1427, 1998.

JOHANSSON, K.E. et al. Identification of the causative agent of granulocytic ehrlichiosis in Swedish dogs and horses by direct solid phase sequencing of PCR products from the 16S r RNA gene. Research in Veterinary Science, v.58, p.109-112, 1995.

KEEFE, T.J. et al. Distribution of Ehrlichia canis among military working dogs in the world and selected civilian dogs in the United States. Journal of American Veterinary Medicine Association, v.181. n.03, p.236-238, 1982.

KELLY, P.J. et al. Serological evidence for antigenic relationships between Ehrlichia canis and Cowdria ruminatium. Research in Veterinary Science, v.56, p.170174, 1994.

KEYSARY, A. et al. The first isolation, in vitro propagation, and genetic characterization of Ehrlichia canis in Israel. Veterinary Parasitology, v.62, p.331-340, 1996.

KNOWLES, R.C. et al. Acute Equine Diarrhea Syndrome (AEDS): A Preliminary Report. American Association of Equine Practicioners- USA, p.353-357, 1983.

KOCAN, A. et al. Naturally occuring Ehrlichia chaffeensis infection in coyotes from Oklahoma. Emerging Infectious Diseases, v.06, n.05, p.477-480, 2000.

KORDICK, S.K. et al. Coinfection with Multiple Tick-Borne Pathogens a Walker Hound Kennel in North Carolina. Journal of Clinical Microbiology, v.37, n.8., p.2631-2638, 1999.

KUEHN, N.F.; GUANT, S.D. Clincal and hematological findings in canine ehrlichiosis. Journal of American Veterinary Medical Association, v.186, n.4, p.355-358, 1985.

LAPPIN, M.R. Feline Ehrlichiosis. In Greene, C.E; Harvey, J.W. (Ed): Infectious Diseases of the Dog and Cat, p.149154, 1998.

LEWIS, G.E. et al. Experimental Induced Infection of Dogs, Cats, and Nonhuman Primates with Ehrlichia equi, Etiologic Agent of Equine Ehrlichiosis. American Journal of Veterinary Research, v.36, n.1, p.85-88, 1975.

LEWIS, G.E. et al. The Brown Dog Tick Rhipice-phalus sanguineus and the Dog as Experimental Hosts of Ehrlichia canis. American Journal of Veterinary Research, v.38, n.12, p.1953-1955, 1977.

MADIGAN, J.E. Equine Ehrlichiosis. Veterinary Clinics of North America: Equine Practice, v.9, n.2, p.423-428, 1993.

MADIGAN, J.E. et al. Equine Granulocytic Ehrlichiosis in Connecticut Caused by an Agent Resem-bling the Human Granulocytotropic Ehrlichia. Journal of Clinical Microbiology, v.34, n.2, p.434-435, 1996.

MAEDA, K. et al. Human infection with Ehrlichia canis, a leukocytic rickettsia. The New England Journal of Medicine, v.316, n.14, p.853-856, 1987. 
MAGNARELLI, L.A.; ANDERSON, J.F. Serologic evidence of canine and equine ehrlichiosis in Northeastern United States. Journal of Clinical Microbiology, v.31, n.11, p.2857-2860, 1993.

MASSARD, C.A.; MASSARD, C.L. Ehrlichiose bovina no Brasil: Ocorrência e avaliação do parasitismo no Estado do Rio de Janeiro e regiões circunvizinhas. In: ANAIS do XVIII Congresso Brasileiro de Medicina Vete-rinária em língua portuguesa e III Semana Brasileira de Parasitologia Veterinária. São Paulo, 1982. p.195.

MATHEW, J.S.; EWING, S.A. Ehrlichiosis. [ on line] . Disponível em: <http://www.su.okstate.edu/students/ sciens/>. Acesso em: 30 jan. 2001.

McDADE, J. Ehrlichiosis-A Disease of Animals and Humans. The Journal of Infectious Diseases, v.161, p.609617, 1989

McQUISTON, J.H. et al. The human Ehrlichiosis in the United States.[on line]. Disponível em: <http://www. medscape.com/govmt/CDC/EID/199....n05/c0505.04. mcqu/pnt-c0505.04mcqu.htmL>. Acesso 13 fev. 2000.

MEINKOTH, J.H. et al. Morphologic and molecular evidence of a dual species Ehrlichial infection in a dog presenting with inflamatory central nervous system disease. Neurology Journal ClubAricle\#1.[ on line] . Disponível em: <http://www. neuro.vetmed.ufl.edu/neuro/neuro/Journal_Club/Articles/ Ehrlichia_Art.hm>. Acesso em 7 abr. 2001.

MORAIS, J.D. et al. First European case of Ehrlichiosis. The LANCET, v.338, p.633-634, 1991.

MURPHY, G.L. et al. A molecular and serologic survey of Ehrlichia canis, E. chaffeensis, and E. ewingii in dogs and ticks from Oklahoma. Veterinary Parasitology, v.79, p.325339, 1998.

NEER, T.M. et al. Efficacy of enrofloxacin for the treatment of experimentally induced Ehrlichia canis infection. Journal of Veterinary Internal Medicine, v.13, p.501-504, 1999.

NYINDO, M. et al. Cell-mediated and humoral immune responses of German Shepherd and Beagles to experimental infection with Ehrlichia canis. American Journal of Veterinary Research, v.41, n.2, p.250-254, 1980.

NYINDO, M.B.A. et al. Tropical Canine Pancytopenia: in Vitro Cultivation of the Causative Agent - Ehrlichia canis. American Journal of Veterinary Research , v.32, n.11, p.1651-1659, 1971.

PANCHOLI, P. et al. Ixodes dammini as a Potencial Vector of Human Granulocytic Ehrlichiosis. The Journal of Infectious Diseases, v.172, p.1007-1012, 1995.

PATEL, R.G., BYRD, M.A. Near fatal acute respiratory distress syndrome in a patient with human ehrlichiosis. South Medical Journal, v,92, n.3, p..333-335, 1999.

PERILLE, A.L.; MATUS, R.E. Canine Ehrlichiosis in six dogs with persistently increased antibody titers. J. Vet. Int. Med., v.5, n.3, p. 195-198, 1991.

PETERSEN, L.R. et al. An Outbreak of Ehrlichiosis in members of na Army Reserv Unit Exposed to Ticks. The Journal of Infectious Diseases, v.159, n.03, p.562-568, 1989.

PETROVEC, M. et al. Human Disease in Europe Caused by a Granulocytic Ehrlichia Species. Journal of Clinical Microbiology, v.35, n.06, p.1556-1559, 1997.

REARDON, M.J.; PIERCE, K.R. Acute experimental canine ehrlichiosis. II. Sequential reaction of the Hemic and Lymphoreticular system of selectively immuno-suppressed dogs. Veterinary Pathology, v.18, p.384-395, 1981.

RIKIHISA, Y. The Tribe Ehrlichieae and Ehrlichial Diseases. Clinical Microbiology Reviews, v.4, n.3, p.286-308, 1991.

RIKIHISA, Y.; PERRY, B.D. Causative agent of Potomac horse fever. The Veterinary Record, Letters, November 24, p.554, 1984.

RISTIC, M. et al. Serological diagnosis of tropical canine pancytopenia by indirect immunofluo-rescence. Infection and Immunity, v.6, n.3, p.226-231, 1972.

RISTIC, M. et al. Evidence of a serologic relationship between Ehrlichia canis and Rickettsia sennetsu. The American Journal of Tropical Medicine and Hygiene, v.30, n.06, p.1324-1328, 1981.

SEIBERT, M. et al. Ocorrência de Ehrlichia (Rickettsiales: Rickettsiaceae) em cães conduzidos ao Hospital de Clínicas Veterinárias da Universidade Federal do Rio Grande do Sul-Brasil. Arquivos da Faculdade de Veterinária UFRGS, v.25, n.02, p.84-94, 1997.

SEXTON, D.J. et al. Dual infectiion with Ehrlichia chaffeensis and a spotted fever group rickettsia: a case report. E.I.D., v.4, n.2, p.311-316, 1998. [on line]. Disponível em: <http:// www.cdc. gov/ncidod/EID/vol4no2/sexton.htm> Acesso em: 8 out. 2000.

SILVEIRA, J.M. et al. Patologia e clínica da ehrlichiose canina no Estado do Mato Grosso do Sul, Brasil. In: Congresso Brasileiro de Medicina Veteri-nária, 19, 1984, Belém. Belém, Sociedade Brasileira de Medicina Veterinária, Sociedade dos Médicos Veterinários do Pará, 1984, p.389.

SIMPSON, C.F. Structure of Ehrlichia canis in blood monocytes of a dog. American Journal of Veterinary Research, v.33, n.12, p.2451-2454, 1972.

SMITH, R.D. et al. Development of Ehrlichia canis, Causative Agent of Canine Ehrlichiosis, in the Tick Rhipicephalus sanguineus and Its Differentiation from a Symbiotic Rickettsia. American Journal of Veterinary Research , v.37, n.02, p.119-126, 1976.

STEIN, A.; RAOULT, D. A simple method for amplifica-tion of DNA from paraffin-embedded tissues. Nucleic Acids Research, v.20. n.19, p.5237-5238, 1992.

STEPHENSON, E.H.; OSTERMAN, J.V. Canine Peritonea Macrophages: Cultivation and Infection with Ehrlichia canis. American Journal of Veterinary Research , v.38, n.11, p.1815-1819, 1977.

STOCKHAM, S.L. et al. Experimental Transmission of Granulocytic Ehrlichial Organisms in Dogs. Veterinary Clinical Pathology, v.19, n.4, p.99-104, 1990.

SUKASAWAT, J.; HEGARTY, B.C.; BREITSCHWERDT, E.B. Seroprevalence of Ehrlichia canis, Ehrlichia equi, and Ehrlichia risticci in sick dogs from North Carolina and Virginia. Journal of Veterinary Internal Medicine, v.14, p.50$55,2000$.

TRESAMOL, P.V.; DINAKARAN, M.; SURESH, S. Serological diagnosis of Ehrlichia canis infection in dogs. Cheiron, v.27, n.3\&4, p.52-54, 1998.

TROY, G.C.; VULGAMOTT, J.C.; TURNWALD, G.H. Canine Ehrlichiosis: A Retrospective Study of 30 Naturally Ocurring 
Cases. Journal of American Animal Hospital Association, v.16, p.181-187, 1980.

VANDERBILT MEDICAL CENTER. Infectious Diseases Ehrlichiosis, 1998. [on line]. Disponível em: <http:// www.mc.vanderbilt.edu/peds/pidl/infect/ehrlich.htm> Acesso em: 8 out. 2000.

VERSALOVIC, J.; KOEUTH, T.; LUPSKI, J.R. Distribuition of repetitive DNA sequences in eubacteria and application to fingerprinting of bacterial genomes. Nucleic Acids Research, v.19 (24), p.6823-6831, 1991.

WALKER, J.S. et al. Clinical and Clinicopathologic Findings in Tropical Canine Pancytopenia. Journal of American Veterinary Medicine Association, v.157, n.01, p.43-55, 1970.

WANER, T.; HARRUS, S. Canine Monocytic Ehrlichiosis (CME). In: CARMICHAEL, L.E. (Ed.) Recent Advances in Canine Infectious Diseases, International Veterinary Information Service (www.ivis.org). [on line]. Disponível em:<http://www.ivis.org/advances/Infect_Dis_Carmichael/ waner/chapter.asp>. Acesso em: 20 out. 2000.

WANER, T. et al. Characterization of the subclinical phase of canine ehrlichiosis in experimen-tally infected beagle dogs. Veterinary Parasitology, v.69, p.307-317, 1997.
WANER, T. et al. Detection of Ehrlichial antigen in plasma of beagle dogs with experimental acute Ehrlichia canis infection. Veterinary Parasitology, v.63, p.331-335, 1996.

WEAVER,,R.A.G., VIRELLA, G., WEAVER, A. Ehrlichiosis with severe pulmonary manifestations despite early treatment. South. Med. J., P.336-339, 1999 [on line]. Disponível em: <http:// www.medscape. com/SMA/SMJ/1999/v.92.n03/ smj9203.13.weav/smj9203.13.weav-01.htmL>. Acesso em: 20 out. 2000 .

WILLIAMS, B. Species jump: Human ehrlichiosis- Mutant or Emergence? [on line]. Disponível em: <http:// www.doofus.org/mercatroid/Ehrlichia.htmL>. Acesso em: 8 out. 2000.

WOODY, B.J.; HOSKINS, J.D. Ehrlichial Diseases of Dogs. Veterinary Clinics of North America: Small Animal Practice, v.21,n.01,p.75-99, 1991.

YAMAMURA, M.H.; VIDOTO, O. Prevalência de hemoparasitos em cães da região norte do Paraná. Congresso Brasileiro de Medicina Veterinária, p.196, Balneário Camboriú, 18 a 23 de outubro de 1982. 
